\title{
SIMULATION MODEL IN A FREE AND OPEN-SOURCE SOFTWARE FOR CARBON MONOXIDE EMISSIONS ANALYSIS
}

\author{
João José de Assis Rangel \\ Túlio Almeida Peixoto \\ Ítalo de Oliveira Matias \\ Eduardo Shimoda \\ Universidade Candido Mendes \\ 100 Anita Pessanha St, Pq. São Caetano \\ Campos dos Goytacazes, RJ, 28030-335, BRAZIL
}

Gabriel Lima de Oliveira

Petrobras - Petróleo Brasileiro SA

665 Elias Agostinho St, Centro

Macaé - RJ, 27913-350, BRAZIL

\author{
Leonardo das Dores Cardoso \\ Instituto Federal Fluminense \\ 273 Dr. Siqueira St, Pq. Dom Bosco \\ Campos dos Goytacazes, RJ, 28030-130, BRAZIL
}

\begin{abstract}
This paper describes an analysis of emissions of carbon monoxide (CO) using a discrete event simulator of open source. A simulation model was built to evaluate gas emissions emitted by a fleet of trucks during transportation of raw materials in a typical supply system of sugarcane in producer mills of ethanol. The simulation model was implemented in the open source simulator and a traditional simulator. The model results presented high correlation, with no significant difference between them. It was also possible to contribute with the proposed simulator through a designed component able to account the $\mathrm{CO}$ emissions.
\end{abstract}

\section{INTRODUCTION}

In recent work, Zhou and Kuhl (2011) presented the structure of a toolkit of simulation tools to analyze the emission of greenhouse gases. This toolkit allows the use of discrete event simulation (DES) in systems where factors related to the emission of greenhouse gases can be analyzed. In these systems, the vehicle (truck) is represented as an entity that flows through the logic of the simulation model. Therefore, when an entity is created, the attributes of a truck with the variables that want to visualize are defined for it. The module created by the system is called "Emissions", which the values of the emission of gases generated along the route are calculated and stored. Byrne et al. (2010) also demonstrated that the use of DES can capture the dynamic and stochastic effects aggregated to the emission of gases in logistics systems, thus, being able to show, more precisely, the environmental costs involved in supply chain operations, for example.

Similar to Zhou and Kuhl (2011), the work of Rangel et al. (2012) also presented a model of DES capable of analyzing the emissions of carbon monoxide (CO) produced by a fleet of trucks. This model simulated the $\mathrm{CO}$ emissions, using only the modules inherent to the Arena software. The analysis was applied in a system of sugarcane transport, in sugarcane mills producers of ethanol, and proved to be efficient. 
In the context of the ethanol production, one of the main problems is related to the transportation of sugarcane between the harvest and the mill. The quality of the raw material is directly linked to the shipping time (Rangel et al. 2010). Also in the context of ethanol production, environmental issues such as the control of the emission of pollutant gases and the reduction of waste that affect the environment have become increasingly present in the center of the main organizational decisions. The current sustainable vision of the companies, either because of punishment or by the concern to achieve proper environmentally goals, has led to reconsider the importance of the reduction of the emissions of pollutant gases in the production context, as well as raise the importance of this factor in the making of business decisions (Widok and Wohlgemuth 2011).

On the other hand, the use of computational simulation in Brazilian companies is still unusual due to the high monetary value spent on importation of commercial software for the development of simulation models. An alternative presented is the possibility of using a Free and Open-Source Software (FOSS) simulator, such as the recent Ururau (Peixoto et al. 2011). The Ururau is a discrete event simulator which, being open source, provides more freedom to the modelist. In the development environment of Ururau, the modelist can manipulate from the graphical user interface to the more internal code.

In this sense, this paper describes a model of DES used to evaluate $\mathrm{CO}$ emissions produced by a logistics system consisting of a fleet of trucks for transportation of sugarcane. The simulation model was developed using the Ururau, and the results were compared with another model of the same system developed in the software Arena.

\section{DESCRIPTION OF THE SYSTEM}

A hypothetical transport logistics system of sugarcane in mills producers of ethanol was idealized. Data from this model were obtained from the work of Rangel et al. (2010) and Iannoni and Morabito (2002). Figure 1 shows, schematically, the supply system, which is, typically, found in Brazilian sugarcane mills.

There are five harvest fronts (HF), each providing the same amount of sugarcane for the same mill. Five trucks are allocated to each HF, where the time of departure of trucks from the HF follows the same probability distribution. The distances of each HF to the mill are shown in the legend.

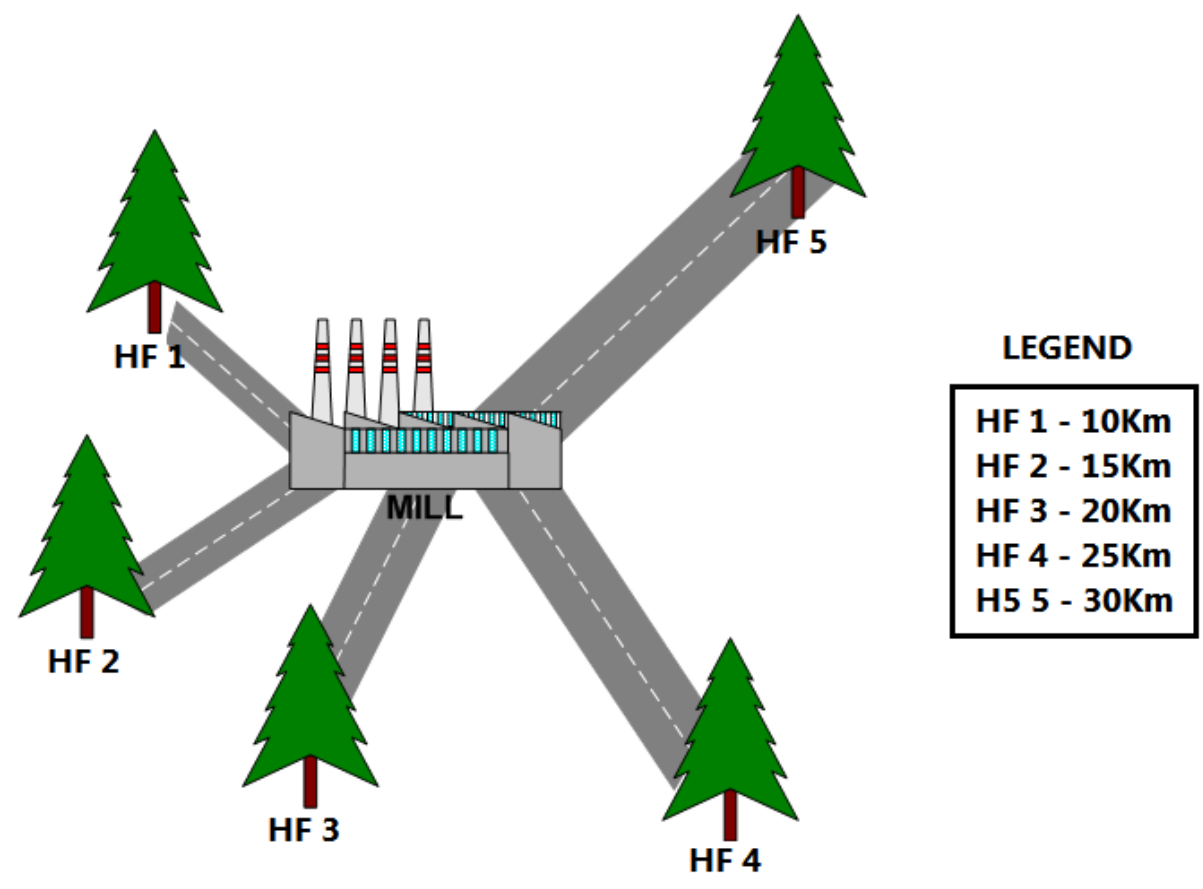

Figure 1: Scheme of the simulated system. 
The system is composed, solely, for the transportation and subsequent unloading of trucks. The loading process of sugarcane in a truck at a HF and the unloading of the respective trucks at the mill are mechanically done. Therefore, it can be considered that the truck engine is turned off at that moment because the time for this case is relatively short, not being emitted polluting gases.

The process is simulated as follows: The trucks already loaded with sugarcane are addressed to the mill in the shortest possible time so as not to compromise the quality of the raw material transported. The trucks wait their turns to unload when arriving at the mill. This waiting process is done with the engine of the trucks off. Therefore, the time in the calculation of the inventory of the $\mathrm{CO}$ emissions is not taken into consideration. Once unloaded, the trucks return to the HF source in order to restart the transport cycle.

\section{SIMULATION MODEL}

The methodology by Banks (2009) was followed to prepare this simulation project, according to the next steps: formulation and analysis of the hypothetical problem; construction of the conceptual model; construction of the simulation model; verification and validation; experimentation; and interpretation and statistical analysis of the results.

From the IDEF-SIM technique (Montevechi et al. 2010), it was possible to construct the conceptual model of the process with a visual aspect of easy understanding and logic similar to that used in programming of the computational model. The conceptual model to carry out computer simulations was translated into Ururau and Arena (Kelton, Sadowski, and Sturrock 2009). Figure 2 shows the conceptual model of the system.

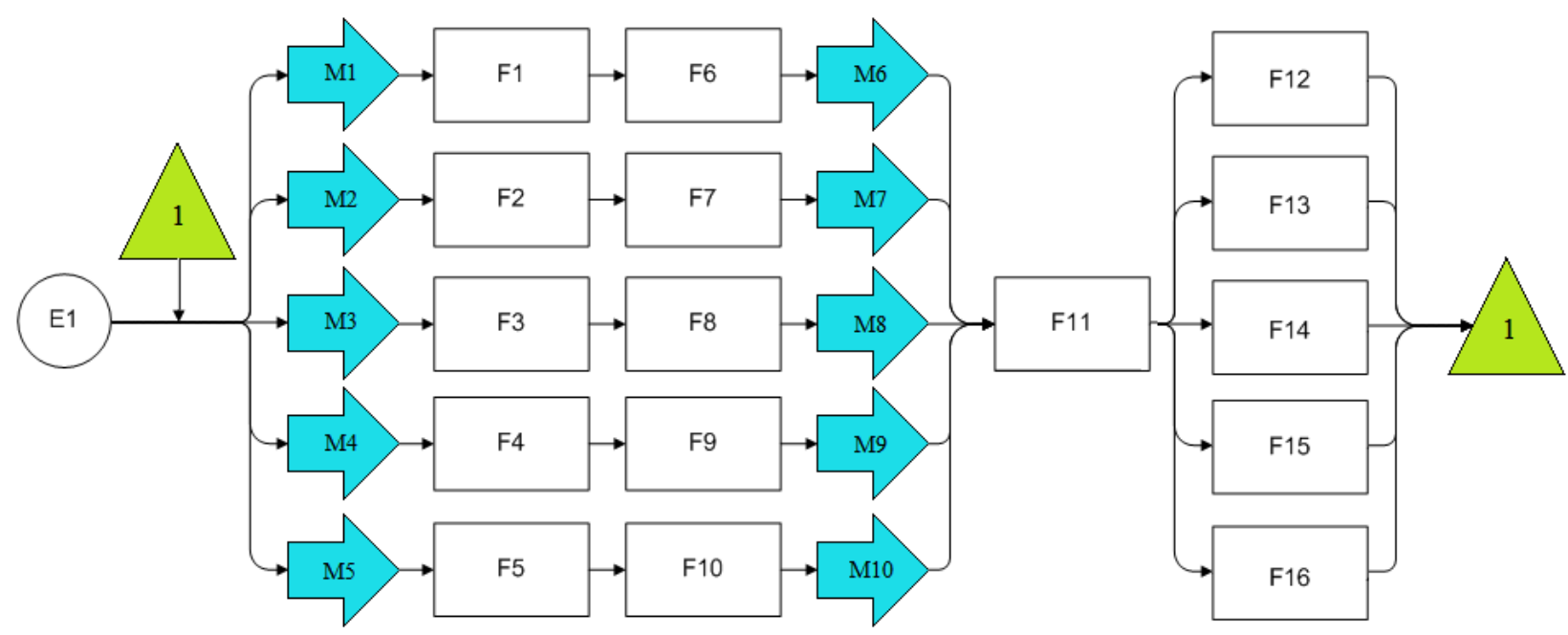

Figure 2: Conceptual model of the system.

It was used, in addition, the methodology proposed by Sargent (2011) for verification and validation of the model. It is worth mentioning that the computational model was constructed after the conceptual model was performed, fully verified and validated.

The simulated system begins with the time needed, by the simulation model, for the departure of each truck (E1) to the corresponding HF. This path has variable time since they are at different distances from the mill and may suffer changes generated by factors as traffic.

Then, the trucks go to their respective HF (M1, M2, M3, M4 and M5). In that way, the pollutants are emitted, with emissions recorded in $\mathrm{CO}$ emissions inventory through the functions F1, F2, F3, F4 and F5. After arriving at the HF, the trucks are loaded (F6, F7, F8, F9 and F10). The loading and unloading periods of time are not considered in the emissions inventory since they are performed with the engine off. 
Once loaded, the trucks return to the mill. This step is represented by functions M6, M7, M8, M9 and M10. There, they wait until the unloading of sugarcane is done (F11). The functions F12, F13, F14, F15 and F16 register the emissions generated by their return to the mill. After this process is conducted, a new loading cycle is started.

\section{URURAU SIMULATION ENVIRONMENT}

The Ururau is the extension of the project of the Java Simulation Library (JSL), proposed by Rossetti (2008). Figure 3 shows the architecture of the Ururau. It was used the Java language in all layers. The library JSL is in the lower layer and converts the model, which consists of a series of process commands, into a sequence of discrete events. The middle layer is the core of the Ururau, which is composed of commands of the JSL processes, such as creation of entities, Seize, Delay, Release, among others. The uppermost layer is the conversion of the graphic model, which comprises a graph directed to a sequence of commands of the Ururau core.

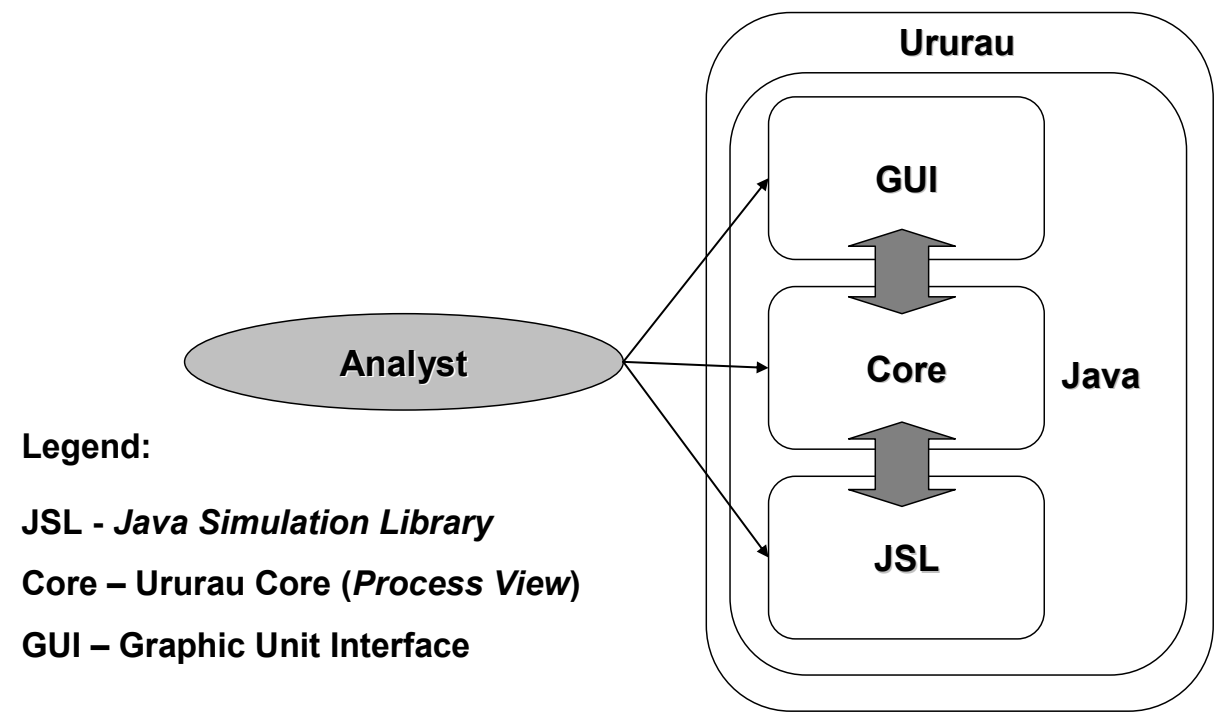

Figure 3: Arquitetura do Ururau.

Figure 4 shows the graphical interface of the Ururau. The purpose of the graphical interface is to facilitate the creation of simulation models. Note that, in Figure 4, the set of functions (Modeling Elements) is on the left. These, in turn, are built by the analyst on the desktop (Desktop). At the bottom left, an overview of the model is presented, if it does not fit on the screen. The representation language of the model is based on the IDEF-SIM. For the construction of the simulation model, the modeler needs only to drag and drop with the mouse the modeling elements to the desktop, according to the logic of the system under analysis. Then, the module is edited by clicking with the right button on it to open it. In the edit box, the data of the model can be inserted as the times of events, the operating rules of the system, among other functions.

The development team of the Ururau uses the versions controller for FOSS named Bitbucket. The Bitbucket is a site for collaborative development, i.e., allows multiple developers working on the same source code. Thus, the interested developer in cooperating registers and the project manager allows the developer submitting the code changes to the site. However, everyone has access to the code without having to register. In other words, just install the Mercurial (https://mercurial.selenic.com), and make the command "hg clone https://bitbucket.org/ururau/ururau".

Then, for the development and use of the Ururau, the site https://bitbucket.org/ururau can be freely accessed. After downloading the zip file, unzip it into a directory and run ururau.jar. You must have Java 
installed on your computer Enviromment Runtime (JRE) version 6.0 or higher, which can be obtained in http://java.com/getjava.

To build the model using the source code, it is necessary a development environment - Integrated Development Environment (IDE), preferably NetBeans 7.0, which can be obtained in http://www.netbeans.org. The environment of the Ururau is composed, internally, by one or more process commands, which extend JSL functionalities. The file README.TXT, which presents an explanation of how each command works, can also be downloaded at the address of the software.

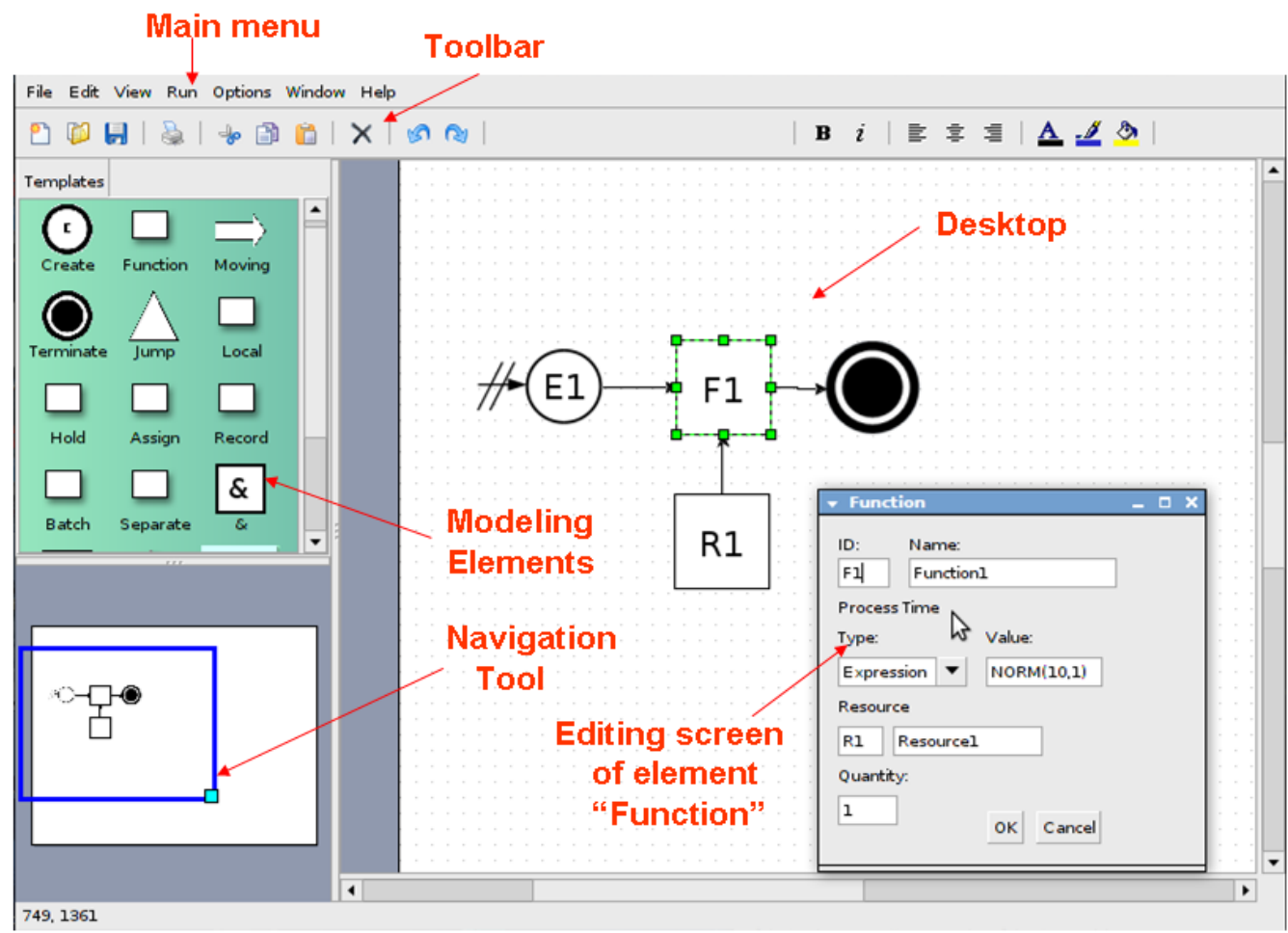

Figure 4: Interface of the Ururau.

\section{SIMULATED EXPERIMENTS}

For the execution of the experiments, it was followed the Resolution 315/02 of CONAMA (National Council of Environment, governmental body of pollutants in Brazil), which main purpose according to its $1^{\text {st }}$ Art is to "Reduce the emission levels of pollutants in automotive vehicles and promote national technological development, both in design engineering and manufacturing, as in methods and equipment to control the emission of pollutants" (Brasil 2002).

The CONAMA created the PROCONVE (Program of Control of Air Pollution by Motor Vehicles), which follows the model of the Euro standards concerning the rules of emissions of pollutants from automobiles sold in the countries of the European Union (adopted by the European Union since 1991). Table 1 illustrates the situation in Brazil since the beginning of the implementation of such standards (P1) with the PROCONVE in 1989. Currently, the P6 is used with much lower emission levels compared to those allowed from the start. It is observed that while Brazil adopts the P6 that follows the Euro 4 standard, the European Union already adopts the Euro 5 standard. Although the level of CO is the same in Euro 4 and 5 standards, it is noteworthy that the levels of emission of other pollutants have been reduced from one standard to another. 
This study examined only the $\mathrm{CO}$ emission, which occurred during the transportation of the fleet, which randomness is considered by the model in the time factor. The analysis with only one gas (CO) helped achieve the verification and validation of the model with greater precision. Similarly, it was also possible to better evaluate the performance of the new open source simulator.

It was considered that $90 \%$ of the available total power $(130 \mathrm{hp})$ of the truck is used in the transportation of sugarcane from the harvest front to the mill, and that, for being empty, only $40 \%$ of the available power of the truck is used for the return of it from the mill to the HF. Therefore, it is deduced that the emission of pollutants in return is lower due to the inferior quantity of load transported.

Table 1: Emission limit for heavy diesel vehicles.

\begin{tabular}{|ccccc}
\hline PROCONVE & EURO & CO $(\mathrm{g} / \mathbf{k W h})$ & TERM & STANDARD (CONAMA) \\
\hline Phase I (P1) & Without Specification & 14,00 & 1989 a 1993 & Res. 18/86 \\
Phase II (P2) & Euro 0 & 11,20 & 1994 a 1995 & Res. 08/93 \\
Phase III (P3) & Euro 1 & 4,90 & 1995 a 1999 & Res. 08/93 \\
Phase IV (P4) & Euro 2 & 4,00 & 2000 a 2005 & Res. 08/93 \\
Phase V (P5) & Euro 3 & 2,10 & 2006 a 2008 & Res. 315/02 \\
Phase VI (P6) & Euro 4 & 1,50 & 2009 a 2012 & Res. 315/02 \\
Phase VII (P7) & Euro 5 & 1,50 & Starts in 2012 & Res. 403/08 \\
\hline
\end{tabular}

Source: Adapted PROCONVE - Program of Control of Air Pollution by Motor Vehicles

The amount of emissions generated by the burning of the fuel is a function of several parameters, including the fuel type, power of the truck engine and the time that the engine is running (Manicom et al. 1993). The results of this study provided a list of emission coefficients in units of grams per kilowatt hour $(\mathrm{g} / \mathrm{kW} \cdot \mathrm{h})$ for various types of fuels, including diesel, allowing the relation shown in Equation (1):

$$
\mathrm{E}_{\mathrm{X}}(\mathrm{t})=\mathrm{Cco}^{*} \operatorname{Pot}^{*} \mathrm{t}
$$

where the emissions produced "E" of the vehicle "x" over the time interval "t" are equal to the emission coefficient Cco (of the vehicle $\mathrm{x}$ ) times the power of the truck in kilowatts "Pot" times the time " $\mathrm{t}$ " (Zhou and Kuhl 2010).

Table 2 shows the results of the scenarios simulated with the Arena and Ururau. 6 scenarios related to the 6 phases of the gas emissions standards, shown in Table 1, were simulated. The difference between the scenarios is in the emission levels. Scenario 1 follows the standard P1, which limits an emission of $14 \mathrm{~g} / \mathrm{kW}$.h until scenario 6, which uses the data of the standards P6 and P7 $(1.50 \mathrm{~g} / \mathrm{kWh})$.

It can be observed the trend of reduction of $\mathrm{CO}$ emissions while the scenarios range from 1 to 6 . The scenarios were replicated 10 times in each simulation.

The emission reductions generated from HF1 to HF5 remains similar in both the model Arena and in Ururau in each scenario. This relation is because the HFs are at different distances in relation to the mill. Therefore, the HF more distant will emit more CO than the closer to the mill in all scenarios.

It was also noted that, at the time of implementation of the norms of PROCONVE, in 1090 (P1), the emission levels were very high $(400,833 \mathrm{~g} / \mathrm{kWh})$ compared to current emissions levels, which has $42,946 \mathrm{~g} / \mathrm{kWh}$. Thus, in a period of 22 years, there was a reduction of almost $90 \%$ of the levels of CO emissions, that was also observed in the results of the two simulations. 
Rangel, Oliveira, Peixoto, Matias, Shimoda, and Cardoso

Table 2: Results of the scenarios - Data in $\mathrm{g} / \mathrm{kWh}$.

\begin{tabular}{|c|c|c|c|c|c|c|c|c|c|c|c|}
\hline \multirow[t]{2}{*}{ Scenario } & \multirow[t]{2}{*}{ HF } & \multicolumn{2}{|c|}{$\begin{array}{l}\text { Emissions on } \\
\text { Going }\end{array}$} & \multicolumn{2}{|c|}{ Total on Going } & \multicolumn{2}{|c|}{$\begin{array}{l}\text { Emissions on } \\
\text { Return }\end{array}$} & \multicolumn{2}{|c|}{ Total on Return } & \multicolumn{2}{|c|}{ Grand Total } \\
\hline & & Arena & Ururau & Arena & Ururau & Arena & Ururau & Arena & Ururau & Arena & Ururau \\
\hline \multirow{5}{*}{1} & 1 & 47013 & 50773 & \multirow{5}{*}{284602} & \multirow{5}{*}{296313} & 18365 & 19491 & \multirow{5}{*}{109556} & \multirow{5}{*}{110777} & \multirow{5}{*}{394158} & \multirow{5}{*}{407090} \\
\hline & 2 & 53987 & 56927 & & & 21915 & 21555 & & & & \\
\hline & 3 & 58189 & 58773 & & & 22350 & 22276 & & & & \\
\hline & 4 & 59368 & 63480 & & & 23032 & 23380 & & & & \\
\hline & 5 & 66045 & 66360 & & & 23894 & 24075 & & & & \\
\hline \multirow{5}{*}{2} & 1 & 37611 & 40619 & \multirow{5}{*}{227706} & \multirow{5}{*}{237050} & 14708 & 15593 & \multirow{5}{*}{87660} & \multirow{5}{*}{88621} & \multirow{5}{*}{315366} & \multirow{5}{*}{325671} \\
\hline & 2 & 43190 & 45541 & & & 17532 & 17244 & & & & \\
\hline & 3 & 46551 & 47018 & & & 17880 & 17820 & & & & \\
\hline & 4 & 47518 & 50784 & & & 18425 & 18704 & & & & \\
\hline & 5 & 52836 & 53088 & & & 19115 & 19260 & & & & \\
\hline \multirow{5}{*}{3} & 1 & 16455 & 17770 & \multirow{5}{*}{99622} & \multirow{5}{*}{103708} & 6435 & 6822 & \multirow{5}{*}{38352} & \multirow{5}{*}{38771} & \multirow{5}{*}{137974} & \\
\hline & 2 & 18896 & 19924 & & & 7670 & 7544 & & & & \\
\hline & 3 & 20366 & 20570 & & & 7823 & 7796 & & & & 142479 \\
\hline & 4 & 20789 & 22218 & & & 8061 & 8183 & & & & \\
\hline & 5 & 23116 & 23226 & & & 8363 & 8426 & & & & \\
\hline & 1 & 13432 & 14506 & & & 5253 & 5569 & & & & \\
\hline & 2 & 15425 & 16264 & & & 6262 & 6158 & & & & \\
\hline 4 & 3 & 16625 & 16792 & 81323 & 84659 & 6386 & 6364 & 31308 & 31649 & 112631 & 116308 \\
\hline & 4 & 16971 & 18137 & & & 6580 & 6680 & & & & \\
\hline & 5 & 18870 & 18960 & & & 6827 & 6878 & & & & \\
\hline & 1 & 7052 & 7616 & & & 2758 & 2923 & & & & \\
\hline & 2 & 8098 & 8539 & & & 3287 & 3233 & & & & \\
\hline 5 & 3 & 8728 & 8816 & 42695 & 44447 & 3353 & 3341 & 16437 & 16615 & 59132 & 61062 \\
\hline & 4 & 8910 & 9522 & & & 3455 & 3507 & & & & \\
\hline & 5 & 9907 & 9954 & & & 3584 & 3611 & & & & \\
\hline & 1 & 5037 & 5440 & & & 1970 & 2088 & & & & \\
\hline & 2 & 5784 & 6099 & & & 2348 & 2309 & & & & \\
\hline 6 & 3 & 6235 & 6297 & 30496 & 31747 & 2395 & 2386 & 11741 & 11867 & 42237 & 43614 \\
\hline & 4 & 6364 & 6801 & & & 2468 & 2505 & & & & \\
\hline & 5 & 7076 & 7110 & & & 2560 & 2579 & & & & \\
\hline
\end{tabular}

\section{STATISTICAL ANALYSIS OF RESULTS}

Statistical analysis were performed in software "Systems for Analysis Statistics and Genetic" (SAEG 9.1), adopting the 5\% level of significance. We obtained the averages and standard errors of each software (Arena and Ururau) in the two trajectories (round trip) and the 6 scenarios as illustrated in Figure 5, being these averages compared by t-test to verify differences between the software. 
It was also acquired an equation of linear regression of the result observed in the software Arena according to the noticed in the Ururau, shown in Figure 6, where there were no significant differences between the software in any of the scenarios or trajectories.

Also in Figure 6, it can be observed that the results obtained by the two software are related by linear regression, being the equation obtained significant $(\mathrm{P}<0.0001)$ and with a high coefficient of determination $(\mathrm{R} 2=99.8 \%)$. The angular coefficient of the regression $(0.962)$ is close to the value 1 , which shows that the results of the simulation displayed by the Ururau are close to the results obtained by the Arena.

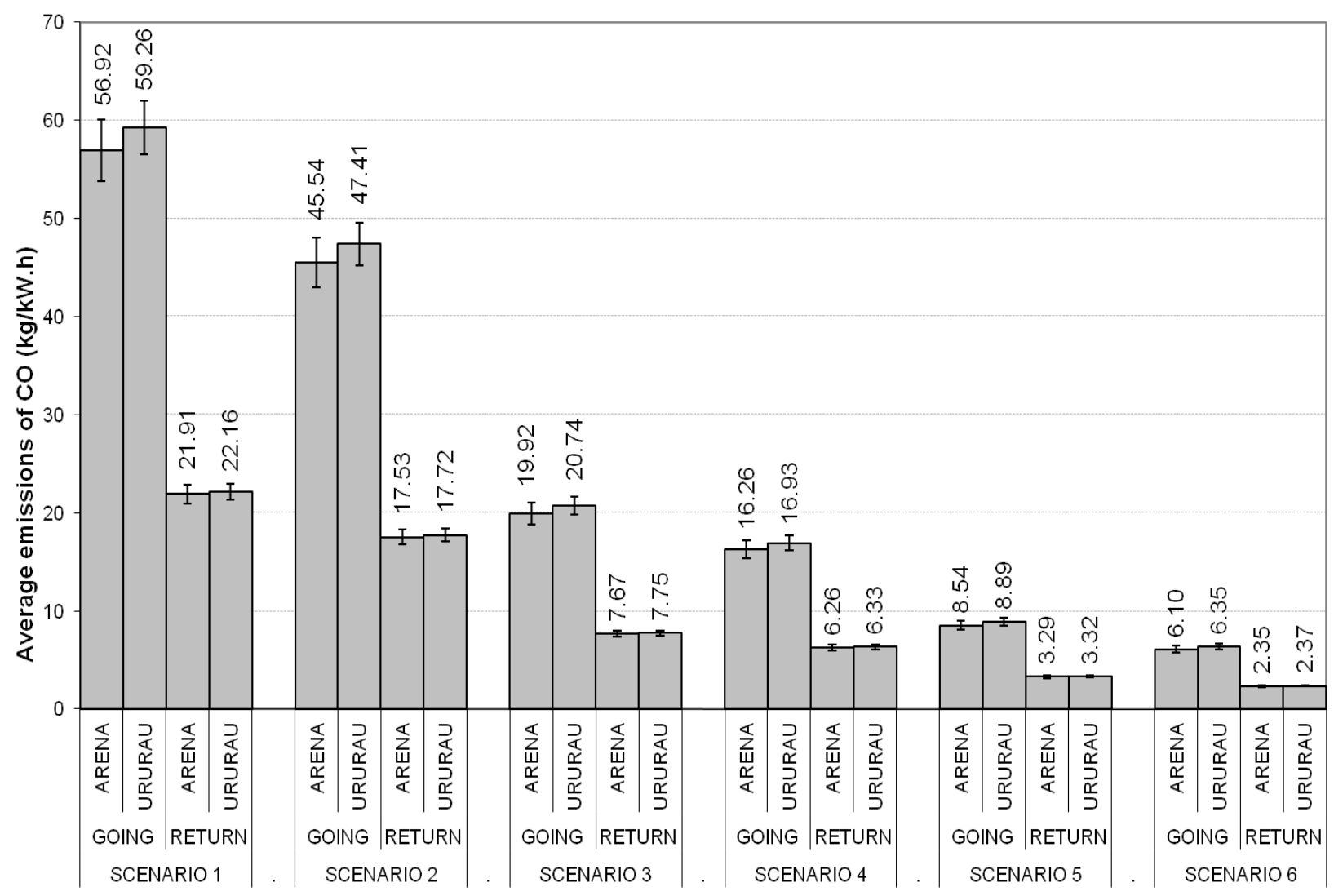

Figure 5: Average emissions of CO. Data in $\mathrm{kg} / \mathrm{kWh}$. 


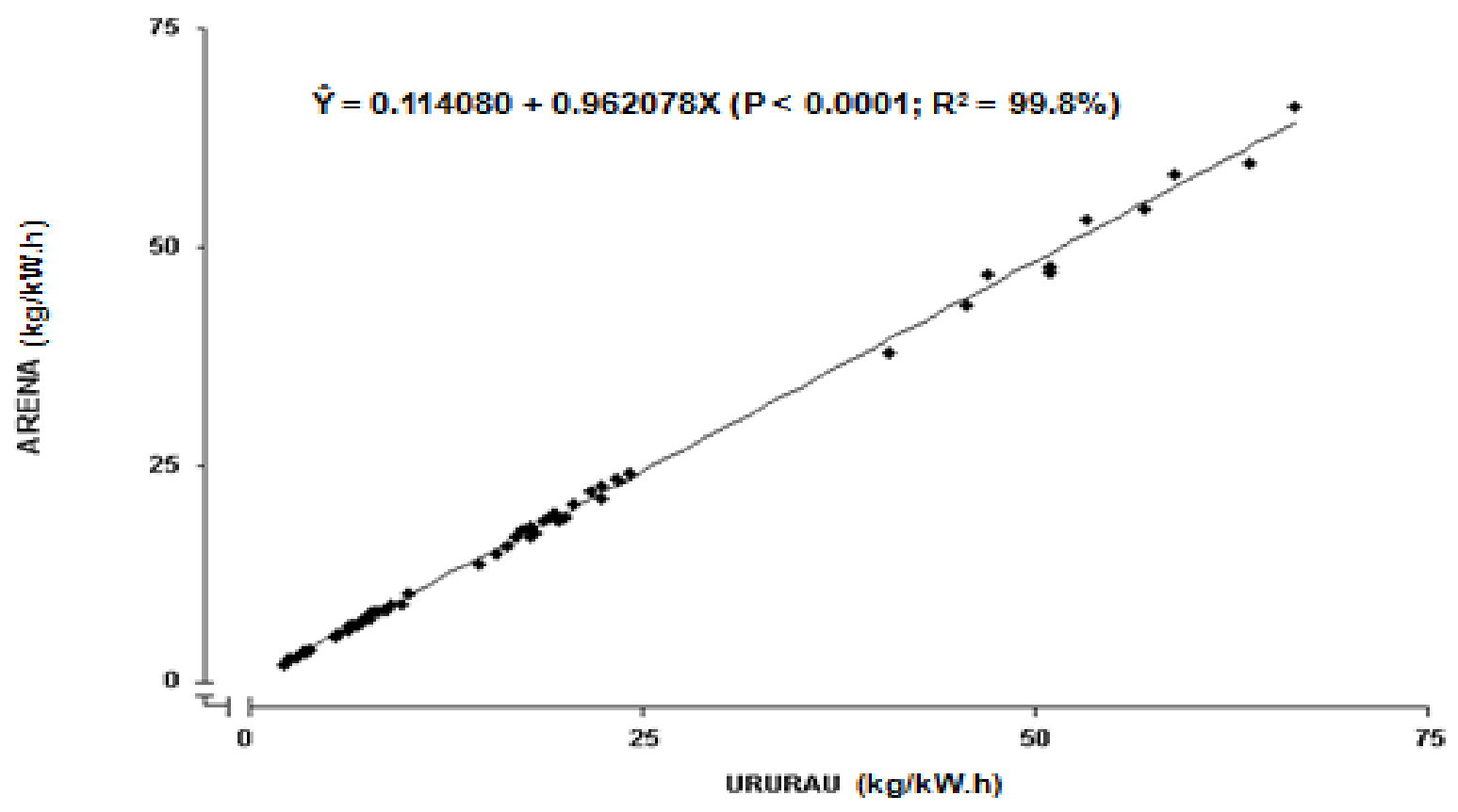

Figure 6: Linear Regression of results of the Arena in function of the Ururau.

\section{CONCLUDING REMARKS}

The simulation model developed in this study corroborated with the raised possibility of being able to analyze the emission of greenhouse gases as a typical discrete event system.

Likewise, the high correlation between the results of the models developed in Ururau and Arena demonstrated the feasibility of being able to build simulation models with the open source simulator Ururau. Furthermore, for being used in different programming levels, open source simulator allowed the development of a component for the proposed model. This fact made the Ururau similarly able to count emissions generated by a fleet of vehicles, such as toolkit developed for the software Arena by Zhou and Kuhl.

The functionality for accounting of emissions was added to the official code of the Ururau, found in its latest version. This was only possible due to the Ururau be an open source simulator, which allows different users to collaborate including other components to the software.

This study compared the analysis only of the $\mathrm{CO}$ emissions. However, the model can be expanded to count the other greenhouse gases such as hydrocarbons, nitrogen oxides, and particulate materials, among others. Also, other models could be performed using mixed fleets (vehicles of different years of manufacture, which meet different emissions standards). Thus, in general, the intention is also, in subsequent steps of this project, extend the analysis to the other gases and, thus, be able to calculate the emissions inventory of a supply chain, for example. 
Rangel, Oliveira, Peixoto, Matias, Shimoda, and Cardoso

\section{ACKNOWLEDGMENTS}

The authors would like to thank the National Council for Scientific and Technological Development $\mathrm{CNPq}$ and the Foundation for Research Support of Rio de Janeiro - FAPERJ for financial support for this research. They also thank Maria Marta Garcia for the translation and suggestions on the English text.

A APPENDIX (Parameters of the Conceptual Model - Figure 2)

\begin{tabular}{|c|c|c|}
\hline CODE & DESCRIPTION & PARAMETER \\
\hline E1 to E5 & Truck & 5 entities; Time of Creation: EXPO (1) min \\
\hline F1 & Transport sugarcane from the HF1 & $\operatorname{NORM}(0.5,0.1)$ hours \\
\hline F2 & Count $\mathrm{CO}$ - Going HF1 & $\begin{array}{c}\text { V_Cont_going } 1+ \\
\left(\mathrm{V} \text { Comb } 1^{*} 0.9^{*} \mathrm{~V} \text { Pot } 1^{*} \mathrm{~V} \text { Temp going } 1\right)\end{array}$ \\
\hline F3 & Unload & $\operatorname{NORM}(5.0,0.5) \mathrm{min}$ \\
\hline F4 & Back to the HF1 & $\operatorname{NORM}(0.45,0.045)$ hours \\
\hline F5 & Count CO - Back HF1 & $\begin{array}{l}\text { V_Cont_Back_1 }+\left(\mathrm{V} \_ \text {Comb_1*0.4* }\right. \\
\text { V_Pot } 1 * \text { V Temp_Back } 1)\end{array}$ \\
\hline F6 & Transport sugarcane from the HF2 & $\operatorname{NORM}(0.7,0.14)$ hours \\
\hline F7 & Count CO - Going HF2 & $\begin{array}{c}\text { V_Cont_Going_2 } \\
(\text { V_Comb_2 } 2 * 0.9 * \text { V_Pot_2 } 2 * \text { V_Temp_Going_2) }\end{array}$ \\
\hline F8 & Back to the HF2 & $\overline{\operatorname{NORM}}(0.63, \overline{0} .063)$ hours \\
\hline F9 & Count CO - Back HF2 & $\begin{array}{c}\text { V_Cont_Back_2 }+\left(\mathrm{V} \_ \text {Comb_2*0.4* }\right. \\
\text { V_Pot_2*V_Temp_Back_2 })\end{array}$ \\
\hline F10 & Transport sugarcane from the HF3 & NORM $(0.9,0.18)$ hours \\
\hline F11 & Count CO - Going HF3 & $\begin{array}{c}\text { V_Cont_Going_3 } 3+ \\
(\text { V_Comb_3 } 3 * 0.9 * \text { V_Pot_3 } 3 * \text { V_Temp_Going_3 })\end{array}$ \\
\hline F12 & Back to the HF3 & NORM $(0.81,0.081)$ hours \\
\hline F13 & Count CO - Back HF3 & $\begin{array}{c}\text { V_Cont_Back_3 }+\left(\mathrm{V} \_C o m b \_3 * 0.4 *\right. \\
\text { V_Pot_3*V_Temp_Back_3 })\end{array}$ \\
\hline F14 & Transport sugarcane from theHF4 & $\overline{\operatorname{NORM}}(\overline{1.1}, 0.2 \overline{2})$ hours \\
\hline F15 & Count CO - Going HF4 & $\begin{array}{c}\text { V_Cont_Going_4 }+ \\
(\text { V_Comb_4 } 4 \text { - } 9.9 * \text { V_Pot_4 } 4 \text { V_Temp_Going_4) }\end{array}$ \\
\hline F16 & Back to the HF4 & $\overline{N O R M}(0.99,0.099)$ hours \\
\hline F17 & Count CO - Back HF4 & $\begin{array}{c}\text { V_Cont_Back_4 }+\left(\mathrm{V} \_ \text {Comb_4 } * 0.4 *\right. \\
\text { V_Pot } 4 * \mathrm{~V} \text { Temp_Back_4 })\end{array}$ \\
\hline F18 & Transportar cana-de-açúcar da FC5 & $\overline{\operatorname{NORM}}(\overline{1.3}, 0.2 \overline{6})$ hours \\
\hline F19 & Count CO - Going HF5 & $\begin{array}{c}\text { V_Cont_Going_5 } \\
(\text { V_Comb_5 } \\
* 0.9 * \text { V_Pot_5 } 5 * \text { V_Temp_Going_5) }\end{array}$ \\
\hline F20 & Back to the HF5 & NORM $(1.17,0.117)$ hours \\
\hline F21 & Count CO - Back HF6 & $\begin{array}{c}\text { V_Cont_Back_5 }+\left(\mathrm{V} \_C o m b \_5 * 0.4^{*}\right. \\
\text { V_Pot_5*V_Temp_Back_5 })\end{array}$ \\
\hline
\end{tabular}

\section{REFERENCES}

Banks, J., J. S. Carson, B. L. Nelson, and D. M. Nicol. 2009. Discrete-Event System Simulation. 5th ed. Upper Saddle River, New Jersey: Prentice-Hall, Inc.

Brasil, D. F. 2002. "Provides for the New Stage of the Program for Vehicle Emission Control PROCONVE." Technical Report No. 315, October 29 DIARY Official Union.

Byrne1, P.J., C. Heavey, P. Ryan, and P. Liston. 2010. "Sustainable Supply Chain Design: Capturing Dynamic Input Factors". Journal of Simulation 4:4:213-221 
Rangel, Oliveira, Peixoto, Matias, Shimoda, and Cardoso

Iannoni, A. P., and R. Morabito 2002. "Análise do Sistema Logístico de Recepção de Cana-de-Açúcar: Um Estudo de Caso Utilizando Simulação Discreta." Gestão e Produção 9:2:107-128.

Kelton, W. D., R. P. Sadowski, and N. B. Sturrock. 2007. Simulation with Arena. 5th ed. New York: Mcgraw-Hill.

Manicom, B., C. Green, and, W. Goetz 1993. Methyl Soyate Evaluation of Various Diesel Blends in a DDC 6v-92 TA Engine. Mississauga, Ontario: Ortech International.

Montevechi, J. A. B., F. Leal, A. F. Pinho, R. F. S. Costa, M. L. M. Oliveira, and A. 1. F. Silva "Conceptual Modeling in Simulation Projects by mean adapted IDEF: an Application in a Brazilian company." In Proceedings of the 2010 Winter Simulation Conference, edited by B. Johansson, S. Jain, J. Montoya-Torres, J. Hugan, and E. Yucesan, 1624-1635. Piscataway, New Jersey: Institute of Electrical and Electronics Engineers, Inc.

Peixoto, T. A., J. J. A. Rangel, and I. O. Matias. "Ururau - Um Ambiente de Simulação a Eventos Discretos." In Proceedings of the 2010 XLIII Simpósio Brasileiro de Pesquisa Operacional (SBPO), $1-2$.

Rangel, J. J. A., A. P. Cunha, L. R. Azevedo, and D. S. Vianna "A Simulation Model to Evaluate Sugarcane Supply Systems." In Proceedings of the 2010 Winter Simulation Conference, Edited by B. Johansson, S. Jain, J. Montoya-Torres, J. Hugan, and E. Yucesan, 2114-2125. Piscataway, New Jersey: Institute of Electrical and Electronics Engineers, Inc.

Rangel, J. J. A., G. L. Oliveira, T. A. Peixoto, L. D. Cardoso, I. O. Matias, and E. Shimoda "Analysis of Carbon Monoxide Emissions in a Open Source Discrete-Event Simulator." In Proceedings of the 2012 Winter Simulation Conference, edited by C. Laroque, J. Himmelspach, R. Pasupathy, O. Rose, and A.M. Uhrmacher, 1-2. Piscataway, New Jersey: Institute of Electrical and Electronics Engineers, Inc.

Rossetti, M. D. 2008. "Java Simulation Library (JSL): An open-source object-oriented library for discrete-event simulation in Java." The International Journal of Simulation and Process Modelling, 4: 1:69-87.

Sargent, R. G. 2011. "Verifications and Validation of Simulations Models." In Proceedings of the 2011 Winter Simulation Conference, edited by S. Jain, R. R. Creasey, J. Himmelspach, K. P. White and M. Fu, 183-198. Piscataway, New Jersey: Institute of Electrical and Electronics Engineers, Inc.

Widok, A. H., and V. Wohlgemuth "Enhancing Event-Discrete-Simulation Software with Sustainability Criteria." In Proceedings of the 2011 The Third International Conference on Advances in System Simulation. Barcelona - Spain. 190-195.

Zhou, X. and Kuhl, M. E. "Design and Development of a Sustainability Toolkit for Simulation." In Proceedings of the 2010 Winter Simulation Conference, edited by B. Johansson, S. Jain, J. MontoyaTorres, J. Hugan, and E. Yucesan,1601-1612. Piscataway, New Jersey: Institute of Electrical and Electronics Engineers, Inc.

Zhou, X. and Kuhl, M. E. "A Sustainability Toolkit for Simulation: Recent developments and future capabilities." In Proceedings of the 2011 Winter Simulation Conference, edited by S. Jain, R. R. Creasey, J. Himmelspach, K. P. White and M. Fu, 850-858. Piscataway, New Jersey: Institute of Electrical and Electronics Engineers, Inc.

\section{AUTHOR BIOGRAPHIES}

JOÃO JOSÉ DE ASSIS RANGEL is a professor at Federal Fluminense Institute (IFF) and Candido Mendes University (UCAM-Campos) in Campos dos Goytacazes, RJ - Brazil. He received a doctoral degree in Materials Engineering at UENF in 1998. His research interests include Simulation on Logistics and Manufacturing, Simulation on Super Hard Materials Process and Simulation Education. His e-mail address is joao@ucam-campos.br. 
GABRIEL LIMA DE OLIVEIRA is an Industrial Engineering degree from Candido Mendes University (UCAMCampos) in Campos dos Goytacazes, RJ - Brazil. He is currently an engineer at Petrobras. His e-mail is gabriellima@petrobras.com.br.

TÚlIO ALMEIDA PEIXOTO is a Computer Engineering degree from PUC-Rio in Rio de Janeiro - Brazil and MSc in Operations Research and Computational Intelligence at Candido Mendes University (UCAM-Campos). His e-mail address is tulioap@gmail.com.

ÍTALO DE OLIVEIRA MATIAS is a professor at Candido Mendes University (UCAM-Campos) and researcher in the TEC-GRAPH (PUC-Rio), RJ - Brazil. He received a doctoral degree in Computer Science at UFRJ in 2007. His research interests include Operational Research and Computational Intelligence. His e-mail address is italo@ucam-campos.br.

EDUARDO SHIMODA is a professor at Candido Mendes University (UCAM-Campos). He received a doctoral degree in Animal Science at UENF in 2004. His research interests include Operational Research and Statistic. His e-mail address is shimoda@ucam-campos.br.

LEONARDO DAS DORES CARDOSO is an Industrial Engineering degree from Candido Mendes University (UCAM-Campos) in Campos dos Goytacazes, RJ - Brazil, and a Control and Automation Engineering degree from Federal Fluminense Institute (IFF-Campos) in Campos dos Goytacazes, RJ - Brazil. He is currently a teacher at Federal Fluminense Institute (IFF) and MSc student in Industrial Engineering at UCAM-Campos. His e-mail is leonardo.cardoso@iff.edu.br. 